\title{
Female Sexual Signaling in a Capital Breeder, the European Glow-Worm Lampyris noctiluca
}

\author{
Gautier Baudry (D) - Juhani Hopkins • Phillip C. \\ Watts • Arja Kaitala
}

Received: 3 February 2020 / Revised: 29 November 2020 / Accepted: 22 December 2020 / Published online: 15 January 2021

(C) The Author(s) 2021

\begin{abstract}
Theory predicts that because costs constrain female sexual signaling, females are expected to have a low signaling effort that is increased with passing time until mating is secured. This pattern of signaling is expected to result from females balancing the costs associated with a higher than optimal signaling effort and those costs associated with a low signaling effort that increase the likelihood of delayed mating. We tested whether this prediction applies in the common glowworm Lampyris noctiluca (Coleoptera, Lampyridae), a capital breeding species in which females glow at night to attract males. Contrary to predictions, we found that the duration of female sexual signaling significantly decreased with time. Moreover, when females experienced multiple light/dark cycles within $24 \mathrm{~h}$, both signaling duration and intensity significantly decreased. These results imply that females attempt to signal as much as possible at first, with the decrease in signaling duration and intensity likely being due to female resource depletion. Because in capital breeding females the costs of a delayed mating are likely greater than the costs of sexual signaling, females should mate as soon as possible and thus always invest into signaling as much as possible.
\end{abstract}

G. Baudry $(\bowtie) \cdot J$. Hopkins $\cdot$ A. Kaitala

Ecology and Genetics Research Unit, University of Oulu, PO Box 3000, FI-90014 Oulu, Finland

e-mail: gautier.baudry@oulu.fi

P. C. Watts

Department of Biological and Environmental Science, University of Jyväskylä, 40014 Jyväskylä, Finland
Keywords Sexual signaling costs $\cdot$ Female sexual selection $\cdot$ Female sexual signaling $\cdot$ Capital breeding . Lampyridae $\cdot$ Lampyris noctiluca

\section{Introduction}

The processes that promote or constrain sexual signaling by females remains poorly understood compared with our understanding of the drivers of male ornamentation (Rosenqvist and Berglund 1992; Amundsen 2000; Clutton-Brock 2009; Edward and Chapman 2011; Tobias et al. 2012). While male reproductive success is usually limited by the quantity of mates, female reproductive success has been thought to be limited by access to resources or mate quality. This has led to the acceptance of the Bateman gradient as an explanation to the differences in sexual signaling between males and females, whereby males increase their reproductive success with sexual signaling, while females make their choice based on the quality of the male that can provide the best resources (Bateman 1948; Cunningham and Birkhead 1998). However, the Bateman gradient fails to explain recent evidence that female mate attraction is more common than traditionally recognized (CluttonBrock 2009), which highlights the need to develop an understanding of sexual signaling in females.

Female sexual ornaments are expected to evolve when females have limited access to males (Levitan 2004; Rhainds 2010). However, investment into sexual ornaments is often traded off against investment into other components of female fitness such as 
fecundity. Thus, females that use sexual signals are expected to evolve strategies to minimize the associated cost of signaling. For example, female moths can attract males by emitting pheromones and balance the costs and benefits of sexual signaling by increasing the signaling effort as they age (Umbers et al. 2015). Signaling females are also expected to gather information about whether their reproductive success is likely to be sperm limited and to adjust their signaling effort accordingly (Umbers et al. 2015). Thus, female signaling effort is expected to be lower when male density is high, and, conversely, higher when male density is low. When signaling females have no information about male density, the only cue on male density is the time a female spends signaling unsuccessfully (Umbers et al. 2015). Consequently, females are predicted to start their signaling effort at low levels to minimize signaling costs and increase their signaling effort with time until a mating is secured (Rhainds 2010, 2019; Umbers et al. 2015).

Life-history constraints may affect the trade-offs between signaling, fecundity and maintenance. Many species can continually acquire resources that are then used either for maintenance or reproduction, whereas capital breeders finance their reproduction with resources acquired before their reproductive bout, for example during the larval stage in many capital breeding insects (Stearns 1989, 1992; Bonnet et al. 1999, 2002; Jervis et al. 2005). In capital breeders, this resource limitation may constrain signaling, fecundity and self-maintenance until successful reproduction. Hence, capital breeding females should balance their resource allocation into sexual signaling in relation to the resources they had been able to gather prior to reproduction.

Given the earlier findings (Rhainds 2010, 2019; Umbers et al. 2015) we hypothesized that female signaling effort (measured as glowing intensity and duration) in a capital breeder is initially low and then increases with time, as long as the female has not mated. We tested this hypothesis using the European common glow-worm, a capital breeding species in which wingless and sedentary females glow at night to attract flying males. For this purpose, we (1) measured glowing of unmated females in the laboratory and (2) modified day/ night cycles to manipulate female glowing effort. We quantified variation in signaling (glowing) duration and intensity for each female and each treatment during five nights.

\section{Materials and Methods}

\section{Study Species}

The common glow-worm is a lampyrid beetle in which the predatory larvae mostly feed on snails, whereas adults do not feed and are principally concerned by reproduction (Tyler 2002). Wingless adult females glow at night to attract males, while males fly in search of glowing females (Tyler 2002). Females usually stop glowing soon after mating and lay their eggs within a day (Tyler 2002). In the wild, females glow 1-3 h per night until they mate, with about half of the females glowing for one night only and most females (95\%) glowing for four nights or less (Dreisig 1978; Tyler 2002; Hickmott and Tyler 2011). Females that fail to mate on a given night will glow every successive night until they mate. Therefore, we can assume that the amount of time a female needs to glow is determined by her success in mate attraction. Because the common glow-worm is a capital breeder (adults do not feed Grassé 1949; Tyler 2002), glow-worm reproduction is fueled with a finite amount of stored energy reserves that cannot be replenished. The exact costs of continuous glowing are not known, but in related Photinus (Lampyridae) species, the metabolic cost of flash signaling was found to be relatively low (Woods et al. 2007). However, delayed mating is costly to fecundity: glow-worms (Hopkins 2018) and related species (Wing 1989) lose a significant proportion of their eggs during each $24 \mathrm{~h}$ cycle in which they fail to mate.

In the common glow-worm, males seem to select the female that is the most visible to them, whether the female is alone or in the presence of competitors (Hopkins et al. 2015; Hopkins 2018; Lehtonen and Kaitala 2020). Unlike in firefly species in which both males and females fly, in the common glow-worm males are not known to exhibit any visible courtship, and there is no evidence that males are choosy, other than selecting the first conspicuous female they come across (Lehtonen and Kaitala 2020). Similarly, female glow-worms may have the opportunity to be choosy only if multiple males arrive within a short time window and this is commonly not the case (personal observations).

\section{Collection of Individuals}

Glowing females were collected in southern Finland near Tvärminne Zoological Station $\left(\mathrm{N} 59^{\circ} 50^{\prime}, \mathrm{E} 23^{\circ}\right.$ 
$\left.15^{\prime}\right)$ and Lohja $\left(\mathrm{N}^{\circ} 0^{\circ} 12^{\prime}, \mathrm{E} 24^{\circ} 0^{\prime}\right)$ during the typical reproductive season of the local glow-worm populations, in June and July (2015). We went before sunset to locations where glow-worms were known to occur and collected all glowing females we were able to spot. The locations were from May onward to maximize catching success and reduce the probability that any female had already glowed a previous night. Females were brought to the experimental facilities at Tvärminne Zoological Station on the night of capture and placed in separate jars, with one individual per jar.

\section{Experimental Design}

We quantified temporal changes in female signaling duration and intensity by isolating females from males (because females glow until they mate) and manipulated the light cycle (because females glow only in darkness). We chose a five day study period because most females mate in less than five days in nature, although some females have been found to glow for up to 15 days, if they fail to mate (Dreisig 1978; Hickmott and Tyler 2011). Each female was individually housed in a separate jar, approximately $10 \mathrm{~cm}$ diameter and $3 \mathrm{~cm}$ high, with moist paper as substrate. Females were not able to observe other females during the experiment.

We distributed an equal number of females haphazardly between a control and a high effort light treatment (see below for sample sizes). To simulate day/night cycle, we used fluorescent tubes that were either switched on or off automatically using a timer. In both treatments, the light cycle included $6 \mathrm{~h}$ of darkness and $18 \mathrm{~h}$ of light per day. The light cycle was inverted so that it was dark in the laboratory during daytime and light during night-time for the convenience of experimentation. The control light treatment imitated the length of the natural light cycle at the study site during the experimentation, with a 24-h period consisting of $6 \mathrm{~h}$ of consecutive darkness (from 09:00 to 15:00) followed by $18 \mathrm{~h}$ of consecutive light $(6 \mathrm{D} / 18 \mathrm{~L})$ (Fig. 1). Whether females glow depends on the experienced dark period and less so on the natural (solar) circadian rhythm (Dreisig 1978).

The high effort treatment was designed to increase the amount of glowing duration and intensity. As glow-worm females start to glow in the darkness after a period in light (Dreisig 1978), the high-effort treatment set to simulate three day/night cycles within $12 \mathrm{~h}$. In particular, the high effort treatment consisted of three cycles of $2 \mathrm{~h}$ of darkness and $2 \mathrm{~h}$ of light that were then followed by $14 \mathrm{~h}$ of light $(2 \mathrm{D} / 2 \mathrm{~L} / 2 \mathrm{D} / 2 \mathrm{~L} / 2 \mathrm{D} / 14 \mathrm{~L})$. The first $2 \mathrm{~h}$ of darkness started at 09:00, the second at 13:00, and the last at 17:00. Each bout of $2 \mathrm{~h}$ of darkness together constituted a "night" and were called dark thirds, A (09:00-11:00), B (13:0015:00) and C (17:00-19:00) (Fig. 1).

As females were brought to the laboratory usually around 02:00-04:00 at night, it was the day-light phase in the laboratory at the time females were brought. Because of this, any measurement from their first artificial night (called Day 1) was not included in the statistical analysis, as Day 1 was used as an acclimatation period. This was done to give every female a standardized $18 \mathrm{~h}$ resting period during the day-light phase $24 \mathrm{~h}$ prior to experimentation.

The glowing duration and intensity of each female was measured each day of experiment during each dark periods of both treatments. The glowing duration was measured from the moment a glow was visible until no glow was visible, or until the lights were turned on at the end of the artificial night. The glowing intensity was estimated at approximately two to five minutes intervals, by visual comparison against a green light-emitting diode (LED) of known brightness and color. The brightness of the LED was matched with the glowing intensity through a 12 steps scale (i.e. the LED brightness could be set at step 1, or step 2...). Each step had a known quantifiable brightness ranging from 0 to $30 \mu \mathrm{mol}$ of photons $/ \mathrm{m}^{2} / \mathrm{min}$, which was used in the analyses (instead of the steps) because the equivalent LED brightness had a logarithmic progression. The LED wavelength was $562 \mathrm{~nm}$, matching with female peak glow emission, ranging 546-570 nm (De Cock 2004). Estimation of the glow intensity was made by the same observer for the whole experiment to reduce observer bias. We used this method to estimate glow intensity as this is the most practical and least invasive method available. We are not aware of any method that would reliably measure the glow intensity of several females at the same time and at regular intervals.

We successfully completed the experiment with 16 females in the control treatment, and 14 females in the high effort treatment. We excluded females that died $\left(\mathrm{N}_{\text {control }}=5, \mathrm{~N}_{\text {high effort }}=1\right)$, laid eggs (i.e. indicating a possibility that the females already mated) $\left(\mathrm{N}_{\text {control }}=6, \mathrm{~N}_{\text {high effort }}=4\right)$ or did not glow at all before the end of the experiment $\left(\mathrm{N}_{\text {control }}=1, \mathrm{~N}_{\text {high }}\right.$ effort $=1$ ). Exclusion criteria were established prior to statistical analysis. Although the difference in 
mortality between the control and high effort treatment was non-significant $(5 \mathrm{v} 1, p=0.22)$ we assigned more females to the control treatment, to compensate for the excluded females during the experiment. The high rate of death may be explained by e.g. pathogens or females running out of energy needed for maintenance. Further details about the excluded individuals are available in Supplementary Information 3.

\section{Statistical Analyses}

Analysis were conducted using R v.3.2.2 (R Core Team 2014), using the packages nlme for building the LMMs (Zuur et al. 2009), and lmer and MuMIn to calculate the marginal and conditional $\mathrm{R}^{2}$ (Nakagawa and Schielzeth 2013). A summary of the statistical analyses is available in Appendix Table 2, and the raw data is available as Supplementary Information 1 and 2.

Data were analysed using in total four different linear mixed-effects models (LMMs) (Zuur et al. 2009), as follows. In the first model (LMM1), we compared glow duration between the treatments and consecutive days (Day 2 to Day 5). For each "Day", we used all observations from a period of $24 \mathrm{~h}$ starting at 09:00. In other words, glow duration was the dependent variable, light treatment ("control" vs "high effort") and Day (2 vs 3 vs 4 vs 5) were the fixed factors, and "individual" was denoted as a random factor, to account for the design of repeated measurements. For simplicity of interpretation and limitations of the sample size, the interaction term between the fixed factors (i.e. light treatment and Day) was not included. Glow intensity was analyzed the same way in our second model (LMM2).

To analyze the variation in glow duration and intensity in the dark thirds of the high effort treatment, we built two additional models, one having glow duration (LMM3) and one having glow intensity (LMM4) as the dependent variable. In both models, the dark third (A vs B vs C) was the only fixed factor, and the individual was designated as a random factor to account for the design of repeated measurements. The coefficient of determination $\left(\mathrm{R}^{2}\right)$ of the LMMs were calculated using the method described by Nakagawa and Schielzeth 2013, with the marginal $R^{2}\left(R^{2} m\right)$ indicating the variance in the data explained by the fixed effects, and the conditional $\mathrm{R}^{2}\left(\mathrm{R}^{2} \mathrm{c}\right)$ indicating the amount of variance explained by the entire model (fixed effects and random effects).

\section{Results}

A total of 30 females were included in the analysis, representing $900 \mathrm{~h}$ of observation of female sexual signaling. On average, females glowed $141 \pm 9.5$ (mean $\pm \mathrm{SE}$ ) minutes per night, at an average intensity of $7.9 \pm$ 0.5 (mean \pm SE) $\mu \mathrm{mol}$ of photon $/ \mathrm{m}^{2} / \mathrm{min}$, from day 2 to day 5 (Appendix Table 1).

The first model LMM1 showed that light treatment did not affect the glowing duration (LMM1, $\mathrm{t}_{28}=0.007$, $\mathrm{SE}=31.46 p=0.50$, Appendix Table 1, Fig. 2). Furthermore, counter to our predictions female glowing duration significantly decreased with time (LMM1, $\mathrm{t}_{89}$ $\left.=-2.2, \mathrm{SE}=5.7, \mathrm{R}^{2} \mathrm{~m}=0.02, \mathrm{R}^{2} \mathrm{c}=0.57, p=0.015\right)$, from day 2 to day 5 (Appendix Table 1, Fig. 2).

The second model LMM2 showed that light treatment did not affect the glowing intensity (LMM2, $\mathrm{t}_{28}=$ $0.21, \mathrm{SE}=1.05, p=0.42$, Appendix Table 1, Fig. 5). Also, counter to our predictions, there was no significant variation in female glowing intensity over time (LMM2, $\mathrm{t}_{89}=-0.83, \mathrm{SE}=0.47, \mathrm{R}^{2} \mathrm{~m}=0.006, \mathrm{R}^{2} \mathrm{c}=0.006, p=$ 0.2, Appendix Table 1, Fig. 5).

Within the high-effort treatment, LMM 3 showed that female glowing duration significantly decreased within day from dark third A to C (LMM3, $\mathrm{t}_{152}=-3.4$, $\mathrm{SE}=3.5, \mathrm{R}^{2} \mathrm{~m}=0.08, \mathrm{R}^{2} \mathrm{c}=0.31, p<0.01$; Appendix Table 1, Figs. 3 and 4), with the dark third A lasting on average $55.9 \pm 4.5$ (mean $\pm \mathrm{SE}$ ) minutes and the dark third C $32.2 \pm 1($ mean \pm SE) minutes. Similarly, LMM4 showed that female glowing intensity significantly decreased within day from dark third A to $\mathrm{C}\left(\mathrm{t}_{152}=-2.4\right.$, $\mathrm{SE}=0.65, \mathrm{R} 2 \mathrm{~m}=0.04, \mathrm{R} 2 \mathrm{c}=0.05, p<0.05)$ (Appendix Table 1, Figs. 6 and 7).

\section{Discussion}

Using the common glow-worm as the model, we found that female signaling duration significantly decreased with time the females had spent unmated. This is in contrast with our hypothesis that female sexual signaling effort in capital breeders would start low and increase with time until mating (see also Rhainds 2019). The signaling intensity, in turn, only decreased in the high effort treatment (i.e. from dark period A to C). Together, our results suggest that in this capital breeder, females signal as much as they can, and that the depletion of resources needed for continued glowing may explain the decrease in signaling duration and intensity. 
We suggest that because capital breeding females are resource limited, time passing without mating may be costlier than signaling. Thus, females may be pressured to always signal as long and intensively as possible from the start until they find a mate.

In species where females signal to attract males, investment into signaling is an essential female fitness component, because failing to attract a mate may result in reproductive failure (Rhainds 2010; Bradbury and Vehrencamp 2011). Modelling predict that the costs of over-signaling constrains female signaling effort to an initially low level that subsequently increases until a mating occurs (Umbers et al. 2015; Rhainds 2019). It is thus expected that increased signaling is costlier than additional time failing to mate, and that females can afford the costs of self-maintenance imposed by delayed mating. However, trade-offs between maintenance, fecundity and signaling may affect how females modulate their signaling. Any delays to mating, whether voluntary or imposed, can result in extra costs of maintenance on females at the expense of their fecundity (Vickers 1997; TorresVila et al. 2002; Mori and Evenden 2013; Umbers et al. 2015). This is especially true for capital breeding females, which have a limited amount of resources to accomplish their reproductive bout (Stearns 1992). Our results suggest that, in at least some capital breeding females, a delay in mating is costlier (on fecundity) than signaling. This costliness is likely to result in selection pressures to mate as soon as possible (Stearns 1992).

Our results that signaling duration and intensity in glow-worm females is at high and potentially maximal level already from the beginning of their reproductive efforts support these ideas. Furthermore, the decrease in both duration and intensity of signaling was strikingly visible in the high-effort treatment, with females glowing on average $23.7 \pm 5.5$ (mean $\pm \mathrm{SE}$ ) min shorter on their last dark third (C) than their first dark third (A). Overall, our results indicate that females signal as much as possible, which may be explained by signaling being cheaper than any delay in finding a mate, i.e. delays imposed by maintenance until the next signaling opportunity during the next night.

Typically, there is a trade-off between survival and reproduction: investment in reproduction reduces lifespan (Travers et al. 2015), while increased lifespan reduces fecundity (Vickers 1997; Bonnet et al. 1999,
2002; Torres-Vila et al. 2002; Mori and Evenden 2013). This effect of resource allocation on fecundity may result in signaling constrains in capital breeders, as their finite resources cannot be replaced at a later stage. In case of delayed mating, capital breeding females experience reduced fecundity as fecundity is traded for maintenance (Wing 1989; Vickers 1997; Torres-Vila et al. 2002; Mori and Evenden 2013). In the common glow-worm, delayed mating may have significant costs on female fecundity as females may lose 10-20\% of their eggs if remaining unmated (Wing 1989; Hopkins 2018). Thus, the amount of energy required to stay alive between successive glowing opportunities is higher than glowing for two hours, given then metabolic costs of glowing reported in a related species (Photinus, Woods et al. 2007). In other words, it appears that females do not benefit from signaling at a low level or from not signaling at all in terms of mate attraction. In particular, our finding that glow-worm females maximize their initial signaling effort supports the hypothesis that the best strategy for a female to maximize her fecundity is to quickly attract a mate by signaling at a high rate as soon as she is ready to mate. The decrease in female glowing duration with time, and both duration and intensity decreasing within day for the high-effort treatment, in turn, are consistent with females getting depleted of their resources needed to sustain their glowing effort.

The fact that females were signaling for longer than their natural night but not for the whole duration of the experimental night, and that female signaling duration decreased with time may indicate a trade-off between signaling duration and intensity. This trade-off is potentially explained by the costs associated with glowing. Besides glow-worm bioluminescence using ATP as a source of energy (Woods et al. 2007; Chapman 2012; Shimomura 2012), renewal of the proteins and enzymes used for the glow also imposes costs, although these regeneration costs are not known (Fallon et al. 2016). These additional costs associated with glow renewal, and generally signal maintenance, may contribute towards the trade-off between signaling duration and intensity, limiting the ability of female glow-worms to signal for long duration and at high intensity. Because male glow-worms are attracted to brighter females (Hopkins et al. 2015; Lehtonen and Kaitala 2020), females may always glow intensively to ensure male attraction, at the expense of signal duration. 


\section{Conclusions}

In capital breeders, potential fecundity costs of delayed mating may define female sexual signaling strategy if mating delay is costlier than signaling. Our study shows the potential importance of trade-offs between selfmaintenance and fecundity on signaling pattern. Considering these trade-offs would allow deeper understanding on female sexual signaling patterns in taxa with diverse life histories. Furthermore, investigating whether glow-worm males exhibit any courtship behavior and/or whether females are choosy for some criteria could shed light on how critical it is for females to signal at high intensity as soon as they are ready to mate.
Supplementary Information The online version contains supplementary material available at https://doi.org/10.1007/s10905020-09763-9.

Acknowledgements We would like to thank the Academy of Finland (project number 294664 to AK) and the Finnish Cultural Foundation (grant numbers 00160127 and 00171185 to GB) for funding, as well as the Tvärminne Zoological Station for providing experimental facilities. Also, we would like to thank Topi Lehtonen for all of his comments and feedbacks, especially during the revision of the article.

Funding Open access funding provided by University of Oulu including Oulu University Hospital.

\section{Appendix}

Table 1 Female mean glowing duration (minutes) and intensity ( $\mu \mathrm{mol}$ of photon $/ \mathrm{m}^{2} / \mathrm{min}$ ). Note that the means for dark third A, B and C are calculated without Day 1

\begin{tabular}{|c|c|c|c|c|c|c|c|c|c|}
\hline & day & 1 & 2 & 3 & 4 & 5 & A & B & $\mathrm{C}$ \\
\hline \multirow[t]{6}{*}{ Duration } & average & 57.8 & 153.7 & 145.9 & 155.9 & 108.6 & 55.9 & 53 & 32.2 \\
\hline & SE & 5.4 & 9.5 & 8.8 & 10.8 & 7.8 & 4.5 & 3.7 & 1 \\
\hline & control & 49.7 & 136.7 & 143.8 & 165.5 & 117.7 & $\mathrm{x}$ & $\mathrm{x}$ & $\mathrm{x}$ \\
\hline & SE & 7 & 13.8 & 13.2 & 16.1 & 10.8 & $\mathrm{x}$ & $\mathrm{x}$ & $\mathrm{x}$ \\
\hline & high effort & 67 & 173.21 & 148.21 & 145 & 98.214 & 55.9 & 53 & 32.2 \\
\hline & SE & 8.5 & 12.8 & 12.1 & 14.8 & 11.5 & 4.5 & 3.7 & 1 \\
\hline \multirow[t]{6}{*}{ Intensity } & average & 5.2 & 7.5 & 9.3 & 8.2 & 6.6 & 8.15 & 6.02 & 5.11 \\
\hline & SE & 0.4 & 0.4 & 0.4 & 0.7 & 0.5 & 0.63 & 0.46 & 0.49 \\
\hline & control & 5.1 & 6.4 & 8.9 & 9.8 & 6.2 & $\mathrm{x}$ & $\mathrm{x}$ & $\mathrm{x}$ \\
\hline & $\mathrm{SE}$ & 0.7 & 0.5 & 0.7 & 1.1 & 0.7 & $\mathrm{x}$ & $\mathrm{x}$ & $\mathrm{x}$ \\
\hline & high effort & 5.3 & 8.8 & 9.9 & 6.5 & 7 & 8.15 & 6.02 & 5.11 \\
\hline & SE & 0.6 & 0.5 & 0.5 & 0.6 & 0.8 & 0.63 & 0.46 & 0.49 \\
\hline
\end{tabular}

Table 2 Results of linear mixed-effects model analysis for the direction of glowing duration (minutes) and intensity $\left(\mu \mathrm{mol}\right.$ of photon $/ \mathrm{m}^{2} /$ $\min$ )

\begin{tabular}{lllllllll}
\hline Dependent variable & Factor & $\mathrm{df}$ & $\mathrm{t}$ & $\mathrm{SE}$ & $\mathrm{R} 2 \mathrm{~m}$ & $\mathrm{R} 2 \mathrm{c}$ & $p$ value & model \\
\hline Duration & treatment & 28 & 0.007 & 31.46 & $\mathrm{x}$ & $\mathrm{x}$ & 0.5 & $\mathrm{LMM} 1$ \\
& day & 89 & -2.2 & 5.7 & 0.02 & 0.57 & $0.015^{*}$ & $\mathrm{LMM} 1$ \\
& dark third & 152 & -3.4 & 3.5 & 0.08 & 0.31 & $<0.01^{*}$ & $\mathrm{LMM} 3$ \\
Intensity & treatment & 28 & 0.21 & 1.05 & $\mathrm{x}$ & $\mathrm{x}$ & 0.42 & LMM2 \\
& day & 89 & -0.83 & 0.47 & 0.006 & 0.006 & 0.2 & LMM2 \\
& dark third & 152 & -2.4 & 0.65 & 0.04 & 0.05 & $<0.05^{*}$ & LMM4 \\
\hline
\end{tabular}




\section{Day/night cycle repartition}

\section{Control}

09:00

$15: 00$

...09:00

\begin{tabular}{|l|ll|}
\hline dark & light & $\ldots$ \\
\hline
\end{tabular}

High effort

\begin{tabular}{|c|c|c|c|c|c|c|}
\hline 09:00 & & $13: 00$ & & $17: 00 \quad 19: 00$ & & $\ldots 09: 00$ \\
\hline dark & light & dark & light & dark & light & $\ldots$ \\
\hline dark third $\mathrm{A}$ & & dark third B & & dark third C & & \\
\hline
\end{tabular}

Fig. 1 Day/night cycle repartition

Fig. 2 Female glowing duration from day 1 to day 5 (mean+SE). Control treatment in white, high effort treatment in grey

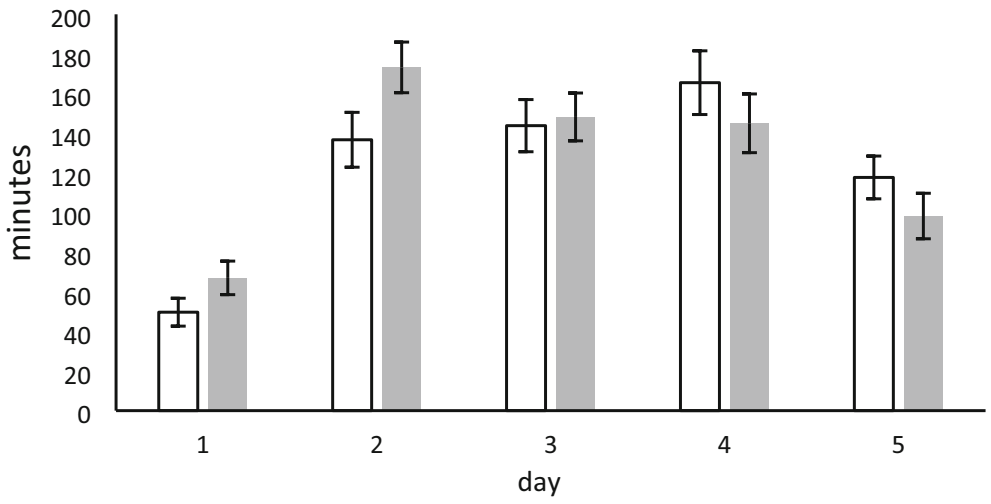

acontrol $\quad$ high effort
Fig. 3 Female glowing duration from day 1 to day 5 (mean+SE) in the High Effort treatment, by dark third A, B and C. In the high effort treatment, the time at which darkness occur was split in three successive dark thirds each lasting $2 \mathrm{~h}$ with $2 \mathrm{~h}$ of day light in between dark third A and B. The first occurring dark third is named $\mathrm{A}$, the second $\mathrm{B}$ and the third $\mathrm{C}$

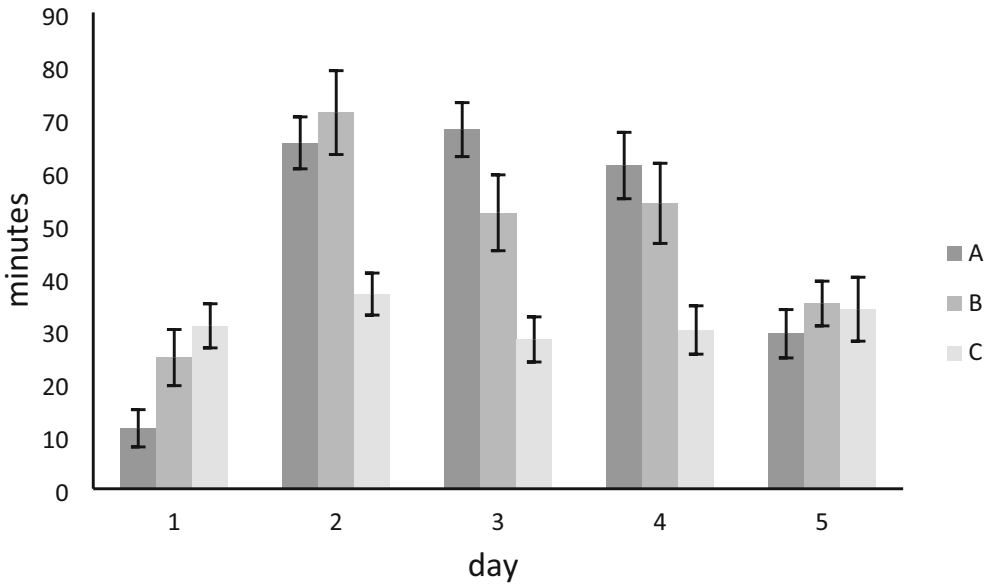


Fig. 4 Female glowing duration (mean+SE) in the High Effort treatment, per dark third (Day 1 not included)

Fig. 5 Female glowing intensity from day 1 to day 5 (mean+SE). Control treatment in white, high effort treatment in grey
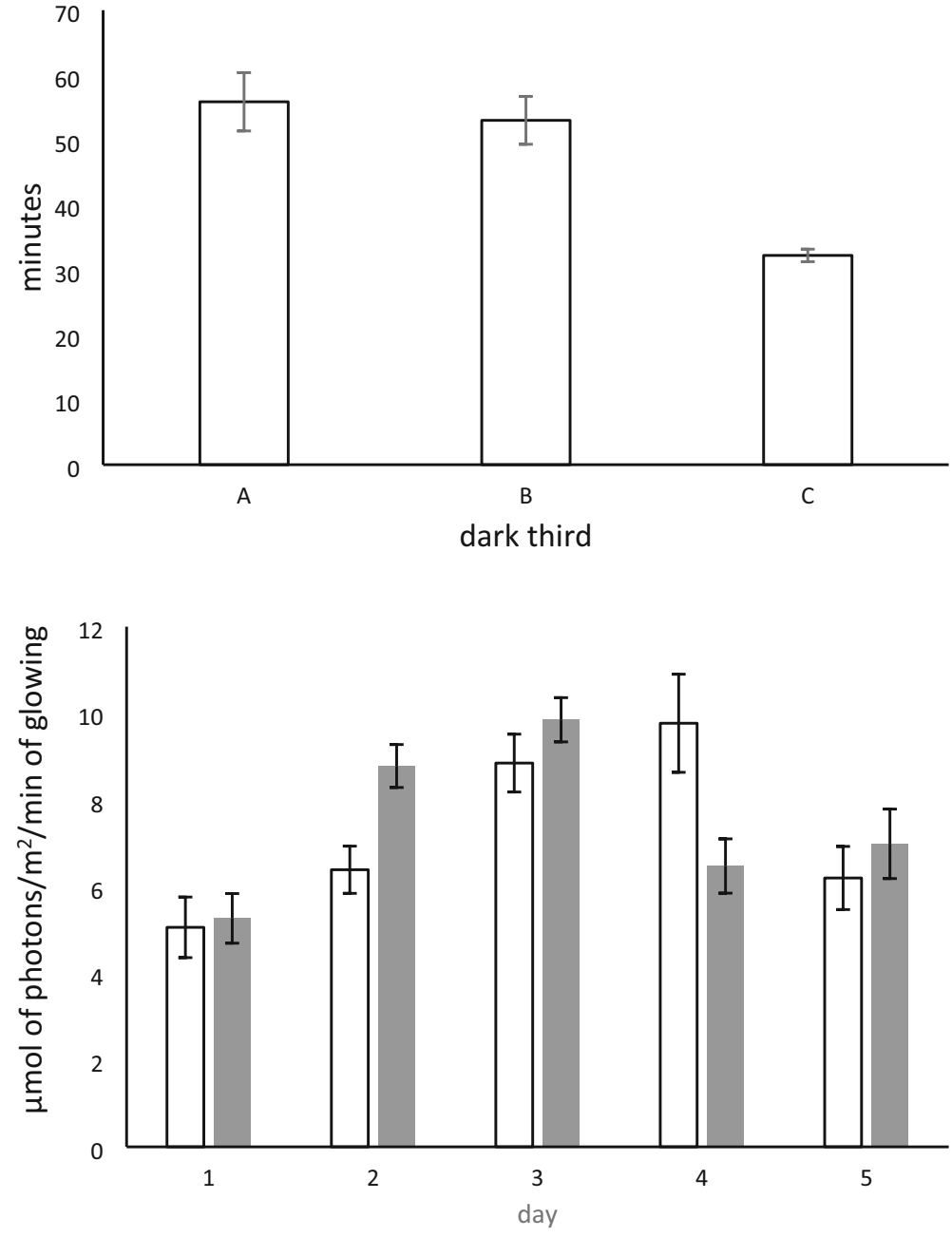

$\square$ control $\quad$ high effort

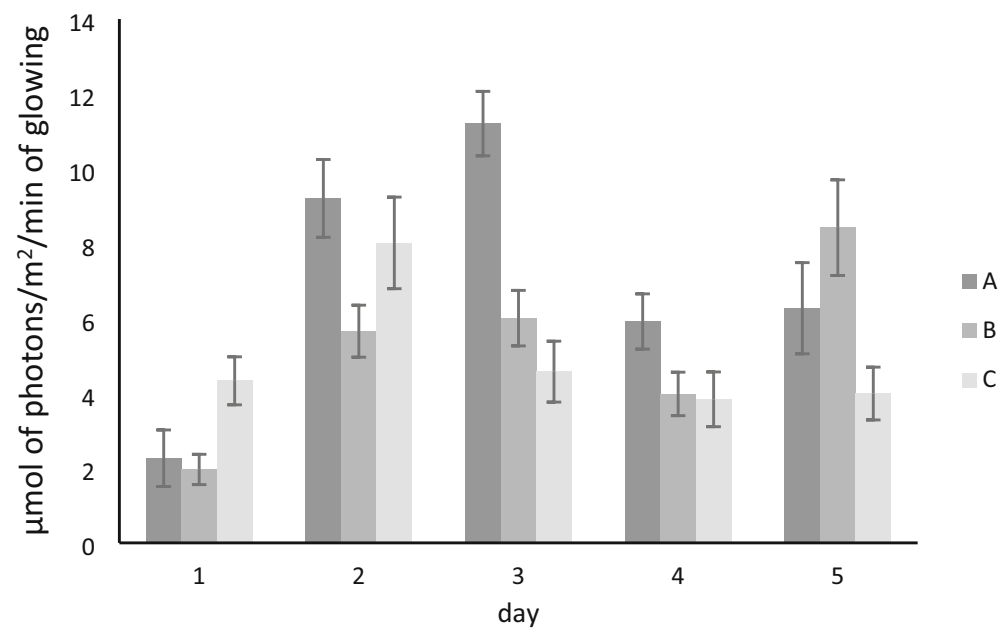


Fig. 7 Female glowing intensity (mean+SE) in the High Effort treatment, by dark third (Day 1 not included)

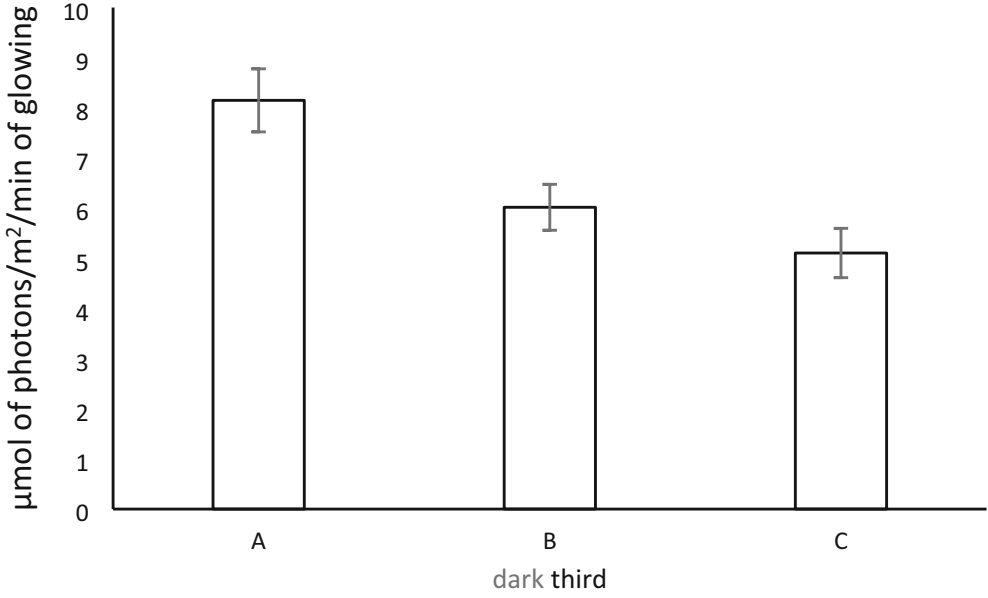

Open Access This article is licensed under a Creative Commons Attribution 4.0 International License, which permits use, sharing, adaptation, distribution and reproduction in any medium or format, as long as you give appropriate credit to the original author(s) and the source, provide a link to the Creative Commons licence, and indicate if changes were made. The images or other third party material in this article are included in the article's Creative Commons licence, unless indicated otherwise in a credit line to the material. If material is not included in the article's Creative Commons licence and your intended use is not permitted by statutory regulation or exceeds the permitted use, you will need to obtain permission directly from the copyright holder. To view a copy of this licence, visit http://creativecommons.org/licenses/by/4.0/.

\section{References}

Amundsen T (2000) Why are female birds ornamented? Trends Ecol Evol 15:149-155

Bateman AJ (1948) Intra-sexual selection in Drosophila. Heredity 2:349-368

Bonnet X, Naulleau G, Shine R, Lourdais O (1999) What is the appropriate timescale for measuring costs of reproduction in a 'capital breeder such as the aspic viper? Evol Ecol 13:485497

Bonnet X, Lourdais O, Shine R, Naulleau G (2002) Reproduction in a typical capital breeder: costs, currencies, and complications in the aspic viper. Ecology 83:2124-2135

Bradbury JW, Vehrencamp SL (2011) Principles of animal communication, 2nd edn. Sinauer Associates, Inc., Sunderland

Chapman RF (2012) The insects: structure and function, 5th edn. Cambridge University Press, New York

Clutton-Brock T (2009) Sexual selection in females. Anim Behav 77:3-11

Core Team R (2014) R: a language and environment for statistical computing. R Foundation, Vienna

Cunningham EJA, Birkhead TR (1998) Sex roles and sexual selection. Anim Behav 56:1311-1321
De Cock R (2004) Larval and adult emission spectra of bioluminescence in three european firefly species. Photochem Photobiol 79:339-342

Dreisig H (1978) The circadian rhythm of bioluminescence in the glowworm, Lampyris noctiluca L. (Coleoptera, Lampyridae). Behav Ecol Sociobiol 3:1-18

Edward DA, Chapman T (2011) The evolution and significance of male mate choice. Trends Ecol Evol 26:647-654

Fallon TR, Li F-S, Vicent MA, Weng J-K (2016) Sulfoluciferin is biosynthesized by a specialized luciferin sulfotransferase in fireflies. Biochemistry 55:3341-3344

Grassé P-P (ed) (1949) Traité de zoologie, anatomie, systématique, biologie: Vol. Tome IX: Insectes : paléontologie, géonémie, Aptérygotes, Ephéméroptères, Odonatoptères, Blattoptéroïdes, Orthoptéroïdes, Dermaptéroïdes, Coléoptères. Masson et Cie, Paris

Hickmott W, Tyler J (2011) Seasonal variation in the female display period of the glow-worm Lampyris noctiluca L. (Coleoptera: Lampyridae). Lampyrid 1:14-21

Hopkins J (2018) The costs and consequences of female sexual signals. Acta Univ Oulu, A 723. PhD dissertation

Hopkins J, Baudry G, Candolin U, Kaitala A (2015) I'm sexy and I glow it: female ornamentation in a nocturnal capital breeder. Biol Lett 11:20150599

Jervis MA, Boggs CL, Ferns PN (2005) Egg maturation strategy and its associated trade-offs: a synthesis focusing on Lepidoptera. Ecol Entomol 30:359-375

Lehtonen TK, Kaitala A (2020) Leave me alone: solitary females attract more mates in a nocturnal insect. Behav Ecol 31: $1040-1045$

Levitan DR (2004) Density-dependent sexual selection in external fertilizers: variances in male and female fertilization success along the continuum from sperm limitation to sexual conflict in the sea urchin Strongylocentrotus franciscanus. Am Nat 164:298-309

Mori BA, Evenden ML (2013) When mating disruption does not disrupt mating: fitness consequences of delayed mating in moths. Entomol Exp Appl 146:50-65

Nakagawa S, Schielzeth H (2013) A general and simple method for obtaining R2 from generalized linear mixed-effects models. Methods Ecol Evol 4:133-142 
Rhainds M (2010) Female mating failures in insects. Entomol Exp App 136:211-226

Rhainds M (2019) Ecology of female mating failure/lifelong virginity: a review of causal mechanisms in insects and arachnids. Entomol Exp App 167:73-84

Rosenqvist G, Berglund A (1992) Is female sexual behaviour a neglected topic? Trends Ecol Evol 7:174-176

Shimomura O (2012) Bioluminescence: chemical principles and methods, Revised edn. World Scientific Publishing Co Pte Ltd, Hackensack

Stearns SC (1989) Trade-offs in life-history evolution. Funct Ecol 3:259-268

Stearns SC (1992) The evolution of life histories. OUP Oxford, Oxford

Tobias JA, Montgomerie R, Lyon BE (2012) The evolution of female ornaments and weaponry: social selection, sexual selection and ecological competition. Philos Trans R Soc B 367:2274-2293

Torres-Vila LM, Rodríguez-Molina MC, Stockel J (2002) Delayed mating reduces reproductive output of female European grapevine moth, Lobesia botrana (Lepidoptera: Tortricidae). Bull Entomol Res 92:241-249

Travers LM, Garcia-Gonzalez F, Simmons LW (2015) Live fast die young life history in females: evolutionary trade-off between early life mating and lifespan in female Drosophila melanogaster. Sci Rep 5:15469

Tyler J (2002) The glow-worm. Lakeside Printing Ltd

Umbers KDL, Symonds RE, Kokko H (2015) The mothematics of female pheromone signaling: strategies for aging virgins. Am Nat 185:417-432

Vickers RA (1997) Effect of delayed mating on oviposition pattern, fecundity and fertility in codling moth, Cydia pomonella (L.) (Lepidoptera: Tortricidae). Aust J Entomol 36:179-182

Wing S (1989) Energetic costs of mating in a flightless female firefly, Photinus collustrans (Coleoptera: Lampyridae). J Insect Behav 2:841-847

Woods WA Jr, Hendrickson H, Mason J, Lewis SM, Marshall AEJ, Whitlock EMC (2007) Energy and predation costs of firefly courtship signals. Am Nat 170:702-708

Zuur A, Ieno E, Walker N, Saveliev A, Graham S (2009) Mixed effects models and extensions in ecology with R. SpringerVerlag, New York

Publisher's note Springer Nature remains neutral with regard to jurisdictional claims in published maps and institutional affiliations. 